Research Article

\title{
Knowledge and Practices on Periodontal Health among Adults, Misungwi, Tanzania
}

\author{
John Michael Nyorobi, ${ }^{1}$ Lorna Celia Carneiro ${ }^{D},{ }^{2}$ and Msafiri Nicodemus Kabulwa ${ }^{3}$ \\ ${ }^{1}$ Dental Unit, Misungwi District Hospital, P. O. Box 8, Misungwi, Mwanza, Tanzania \\ ${ }^{2}$ Department of Restorative Dentistry, Muhimbili University of Health and Allied Sciences, P. O. Box 65451, Dar es Salaam, \\ Tanzania \\ ${ }^{3}$ Oral Health Section, Ministry of Health, Community Development, Gender, Elderly and Children, P. O. Box 743, Dodoma, \\ Tanzania
}

Correspondence should be addressed to Lorna Celia Carneiro; carneiro2@hotmail.com

Received 23 July 2018; Revised 20 September 2018; Accepted 17 October 2018; Published 1 November 2018

Academic Editor: Carlos A. Munoz-Viveros

\begin{abstract}
Copyright (c) 2018 John Michael Nyorobi et al. This is an open access article distributed under the Creative Commons Attribution License, which permits unrestricted use, distribution, and reproduction in any medium, provided the original work is properly cited.
\end{abstract}

\begin{abstract}
The level of knowledge and practices on periodontal health of 388 adults in Misungwi District, Tanzania, was assessed. Analysis included frequency distributions and the chi-square test at a $p$ value of 0.05 . Many more participants were males $(n=197 ; 50.8 \%)$ and of younger age group $(n=215 ; 55.4 \%)$ and having seven years of education $(n=257 ; 66.2 \%)$. Higher number of participants reported owning a mobile phone $(n=289 ; 74.5 \%)$ and a radio $(n=298 ; 76.8 \%)$, while few $(n=45 ; 11.6 \%)$ had their houses connected to electricity. Study participants who were males $(n=101 ; 51.3 \%)$, had more than seven years of schooling $(n=67$; $72.3 \%)$, who owned a mobile phone $(n=143 ; 49 \%)$, owned a radio $(n=144 ; 48.3 \%)$, and resided in houses having electricity ( $n=37 ; 82.2 \%)$ were statistically significantly more knowledgeable on periodontal health when compared to their counterparts. A statistical significant difference was seen in oral health practices conducive to periodontal health among those who were males ( $n=133 ; 67.0 \%)$, having more than seven years of education $(n=78 ; 83.0 \%)$, owning a mobile phone $(n=189 ; 65.4 \%)$, owning a radio $(n=195 ; 65.4 \%)$, and residing in house having electricity $(n=35 ; 77.8 \%)$. This study observed that participants who were males, owned a mobile phone, owned a radio, resided in houses having electricity, and having more than seven years of education were more knowledgeable and had more conducive oral health practices on periodontal health.
\end{abstract}

\section{Introduction}

Periodontal disease is a chronic disease that affects one or more components of the periodontium and is a growing burden to people, healthcare systems, and societies across the world [1]. It refers to the inflammatory processes that occur in the tissues surrounding the teeth in response to bacterial accumulations (dental plaque) [2]. Gingivitis and periodontitis are a continuum of the same inflammatory process [3], and while gingivitis is the presence of gingival inflammation without loss of connective tissue attachment, periodontitis is the presence of gingival inflammation at sites where there has been apical migration of the epithelial attachment onto the root surfaces accompanied by loss of connective tissue and the alveolar bone [4].
Periodontal disease has been associated with self-reported signs and symptoms-like "swollen gums," "sore gums," "receding gums," "loose teeth," "drifting teeth," "bad breath," and "toothache" [5]. Furthermore, severe periodontitis, which may result in tooth loss [6], is found in 5-20\% of most adult populations worldwide [7].

The prevalence of periodontal disease in a population is dependent on risk characteristics like age, sex, education, geographic and environmental status, oral hygiene practices, and social characteristics [8]. In addition, dental awareness, oral health, and oral health-related behaviors have been reported to be influenced also by the socioeconomic status [9], and the link between periodontal disease and socioeconomic status has been reported [10]. Socioeconomic status associated with the health status of an individual 
including oral health has been assessed using various indicators such as owning a television, refrigerator, mobile phone, bicycle, car, utensils, access to utilities (electricity and water), and housing characteristics (materials used for floor, number of rooms, and quality of toilets) [11]. It has been further documented that higher income enables people to afford better housing and permit increased access to healthcare and offers the opportunity to adopt appropriate oral health practices [12].

So as to maintain oral health and prevent the occurrence of periodontal diseases in a population, it is essential that there be acquisition of adequate oral health knowledge together with instilling of appropriate self-care practices [13]. Moreover, prevention of and early intervention into periodontal disease are critical, and successful management of periodontal disease depends on the capacity of patient's oral selfcare practices $[14,15]$. The single most important step an individual can take to reduce plaque accumulation and the consequent risk of plaque-associated diseases, such as periodontitis, is perhaps routinely performing tooth brushing [16]. With regard to frequency of tooth brushing, a previous study demonstrated that individuals who cleaned their teeth at least twice a day exhibited less visible plaque, as compared with those who cleaned their teeth less than once a day or never [17]. However, the benefit of toothpaste in removing plaque during brushing has been controversial [18].

In Tanzania, dental plaque has been reported to be prevalent among adolescents [19] and adults [20], and it is estimated that, on average, at the age of 40 to 49 years, each Tanzanian has lost at least one tooth because of advanced periodontal disease, and after the age of 50, the problem becomes more marked [21]. To address this, an oral health policy to promote primary, secondary, and tertiary levels of oral healthcare to Tanzanians through community involvement particularly in the rural areas was developed [22].

A previous study on oral health issues for the elderly in Tanzania reported that people aged $40+$ years, who live in the rural areas, are at a higher risk of destructive periodontal disease, and it was recommended that oral health education, focusing on behavior change, should be initiated from childhood [23].

Identifying the level of oral health knowledge and practices on periodontal health can assist in planning preventive strategies towards reducing periodontal disease. This study therefore aimed at determining the level of knowledge and practices on periodontal health among adults of Misungwi District in Tanzania.

\section{Materials and Methods}

Misungwi District in Mwanza Region in Tanzania has 4 divisions, 20 wards, 78 villages, and 40,364 households, with a total population of 316,687 people [24]. Using multistage stratified cluster random sampling, two of the four divisions within Misungwi District were selected. Subsequently, in each division, one ward was selected, and from each ward, two villages were chosen. From each village, ten households are grouped and referred to as ten cells, and in each village, 25 ten cells were visited. Adults present in each household within a ten cell were informed of the purpose of the study by the local administrative authority following which consent was obtained. Participants excluded from the study were those below 18 years of age, adults who were nonresidents of Misungwi, and those who were either mentally challenged or sick.

Following consent, a structured self-administered questionnaire that was translated into Kiswahili was used to gather the necessary information from the study participants. The questionnaire was divided into four sections, namely, sociodemographic information, socioeconomic status indicators, assessment of the level of knowledge, and assessment of practices on periodontal health. Pretesting to establish meaning and clarity of the questionnaire was done using a randomly selected group of forty people from one of the villages (Buhunda). Following testing, words and sentences that appeared not clear were rectified and retesting of the questionnaire was done. Reproducibility of the answers ranged between 90 and 100\% indicating adequate reliability of the questionnaire.

Sociodemographic information included details on age (young adults-18-34 years and middle aged to elderly adults-35-74 years), sex (male and female), and level of education (not gone to school, seven years of education, and more than seven years of education).

Socioeconomic status indicators included information on owning a radio (yes $=1$ or no $=0$ ) or mobile phone (yes $=1$ or no $=0$ ) or having electricity in household (yes $=1$ or no $=0$ ).

Level of knowledge on periodontal health was assessed using 6 questions (knowledge on types of oral diseases, presentation of the gum disease, causes of gum disease, effects of gum disease, prevention of gum disease, and harmful effects to the gum due to smoking). Responses to the questions were itemized and coded following which incorrect responses were awarded a zero mark, and correct responses were awarded a mark of one. A count of correct responses to all questions was done, and a subject was regarded as being knowledgeable if three or more of the six questions were correctly answered and not knowledgeable if less than three of the questions were correctly answered.

Level of oral health practice on periodontal health was assessed using 5 questions, namely, use of toothpaste for brushing (yes $=1$ or no $=0$ ), time spent during tooth brushing (less than two minutes during tooth brushing, and two or more minutes during tooth brushing), frequency of tooth brushing (once a day or two or more times a day), having attended a dental health facility (yes $=1$ or no $=0$ ), and practice of smoking (yes $=1$ or no $=0$ ). Responses to the five questions were counted, and participants who scored 3 or more were considered to have practices conducive for periodontal health, while participants who scored below three were regarded as having practices not conducive for periodontal health.

Data processing was done using Statistical Package of the Social Sciences, IBM ${ }^{\mathrm{TM}}$, version 17.0 of 2016 (Chicago, IL, USA). Independent variables were sociodemographic details (age, sex, and level of education) and socioeconomic status indicators (owning a radio or mobile phone or having electricity), while dependent variables were questions on 
oral health knowledge and practices towards periodontal health. Data analysis included frequency distribution and cross tabulation. Frequency distributions of respondent's responses to the questions on knowledge and practice were generated. The chi-square test was performed to identify associations between independent and dependent variables, and a $p$ value of 0.05 was used to determine the level of statistical significance.

Prior to conducting the study, a Research clearance Certificate Number CREC/039/2013 was obtained from the Catholic University of Health and Allied Sciences (CUHAS)/Bugando Medical Centre (BMC) Research Ethical Committee (CREC) and used to obtain permission from the Regional and District authorities of Misungwi.

\section{Results}

A total of 388 adults participated in this study with an age ranging from 18 to 74 years and median age of $32 \pm 0.58$ years. With regard to sociodemographic details, there were slightly more males $(50.8 \%)$ than females and young adults under the age of 35 years (55.4\%). Participants who had not gone to school were the minority $(n=37 ; 9.6 \%)$, while those who had seven years of education were the majority $(n=257 ; 66.2 \%)$. The remaining participants had more than seven years of education $(n=94 ; 24.2 \%)$. On assessment of socioeconomic status indicators, about threequarters $(n=289 ; 74.5 \%)$ owned mobile phones and $76.8 \%(n=298)$ owned a radio, while only few $(n=45$; $11.6 \%)$ had their houses connected to electricity. Owning of a mobile phone and radio among those who had not gone to school was $4.4 \%$ and $7.2 \%$, respectively. About half $(n=190$; $49.0 \%)$ of the participants could mention any oral disease, $68.6 \%(n=266)$ could mention signs and symptoms of periodontal diseases, and about a quarter $(n=103 ; 26.5 \%)$ could mention causes of gum diseases, while $32 \%(n=124)$ and $29.6 \%(n=115)$ could mention effects and prevention of gums diseases, respectively. About a third ( $n=129 ; 33.2 \%)$ were aware on the harmful effects of smoking on gum diseases. Majority of the participants used toothpaste during brushing their teeth $(n=321 ; 82.7 \%)$ and reported to spend two minutes or more during tooth brushing $(n=336$; $86.6 \%)$, while less than half $(n=180 ; 46.4 \%)$ brushed their teeth two or more times a day. A little more than a third $(n=154 ; 39.7 \%)$ had ever attended a dental health facility, and a minority $(n=59 ; 15.2 \%)$ reported that they smoke (Table 1).

Table 2 shows the distribution of the participant's level of knowledge on periodontal health by sociodemographic and socioeconomic variables. Compared to females, male participants were more knowledgeable $(n=101 ; 51.3 \%)$ on periodontal health, and the difference was statistically significant $(p$ value $=0.018)$. With regard to age, there was no statistical significant difference $(p$ value $=0.082)$ between level of knowledge on periodontal health of young adults ( $n=106 ; 49.3 \%$ ) when compared to middle aged to elderly participants $(n=70 ; 40.5 \%)$. Study participants who had
TABle 1: Frequency distribution of the study participants' oral health knowledge and oral health practices on periodontal health by sociodemographic and socioeconomic variables $(n=388)$.

\begin{tabular}{|c|c|c|}
\hline & $\begin{array}{c}\text { Number } \\
(n)\end{array}$ & $\begin{array}{c}\text { Percentage } \\
(\%)\end{array}$ \\
\hline \multicolumn{3}{|l|}{ Sociodemographic variables } \\
\hline \multicolumn{3}{|l|}{ Sex } \\
\hline Male & 197 & 50.8 \\
\hline Female & 191 & 49.2 \\
\hline \multicolumn{3}{|l|}{ Age group } \\
\hline $18-34$ & 215 & 55.4 \\
\hline $35+$ & 173 & 44.6 \\
\hline \multicolumn{3}{|l|}{ Level of education } \\
\hline Not gone to school & 37 & 9.6 \\
\hline Seven years of education & 257 & 66.2 \\
\hline More than seven years of education & 94 & 24.2 \\
\hline \multicolumn{3}{|l|}{ Socioeconomic variables } \\
\hline \multicolumn{3}{|l|}{ Owning a cell phone } \\
\hline Yes & 289 & 74.5 \\
\hline No & 99 & 25.5 \\
\hline \multicolumn{3}{|l|}{ Owning a radio } \\
\hline Yes & 298 & 76.8 \\
\hline No & 90 & 23.2 \\
\hline \multicolumn{3}{|l|}{ House having electricity } \\
\hline Yes & 45 & 11.6 \\
\hline No & 343 & 88.4 \\
\hline \multicolumn{3}{|l|}{ Oral health knowledge } \\
\hline \multicolumn{3}{|c|}{ Can they mention types of oral diseases? } \\
\hline Yes & 190 & 49.0 \\
\hline No & 198 & 51.0 \\
\hline \multicolumn{3}{|c|}{ Can they mention signs and symptoms of periodontal diseases? } \\
\hline Yes & 266 & 68.6 \\
\hline & 122 & 31.4 \\
\hline \multicolumn{3}{|c|}{ Can they mention causes of gum diseases? } \\
\hline Yes & 103 & 26.5 \\
\hline No & 285 & 73.5 \\
\hline \multicolumn{3}{|c|}{ Can they mention effects of gum diseases? } \\
\hline Yes & 124 & 32.0 \\
\hline No & 264 & 68.0 \\
\hline \multicolumn{3}{|c|}{ Can they mention prevention of gum of diseases? } \\
\hline Yes & 115 & 29.6 \\
\hline No & 273 & 70.4 \\
\hline \multicolumn{3}{|c|}{ Awareness on harmful effects of smoking on gums } \\
\hline Yes & 129 & 33.2 \\
\hline No & 259 & 66.8 \\
\hline \multicolumn{3}{|l|}{ Oral health practice } \\
\hline \multicolumn{3}{|c|}{ Use of toothpaste during teeth brushing } \\
\hline Yes & 321 & 82.7 \\
\hline No & 67 & 17.3 \\
\hline \multicolumn{3}{|l|}{ Time spent during tooth brushing } \\
\hline Less than two minutes & 52 & 13.4 \\
\hline Two minutes or more & 336 & 86.6 \\
\hline \multicolumn{3}{|l|}{ Frequency of tooth brushing } \\
\hline Less than twice a day & 208 & 53.6 \\
\hline Twice or more a day & 180 & 46.4 \\
\hline Ever attended dental health facility? & & \\
\hline Yes & 154 & 39.7 \\
\hline No & 234 & 60.3 \\
\hline Do you smoke? & & \\
\hline Yes & 59 & 15.2 \\
\hline No & 329 & 84.8 \\
\hline
\end{tabular}


TABLE 2: Distribution of the participant's level of knowledge on periodontal health by sociodemographic and socioeconomic variables.

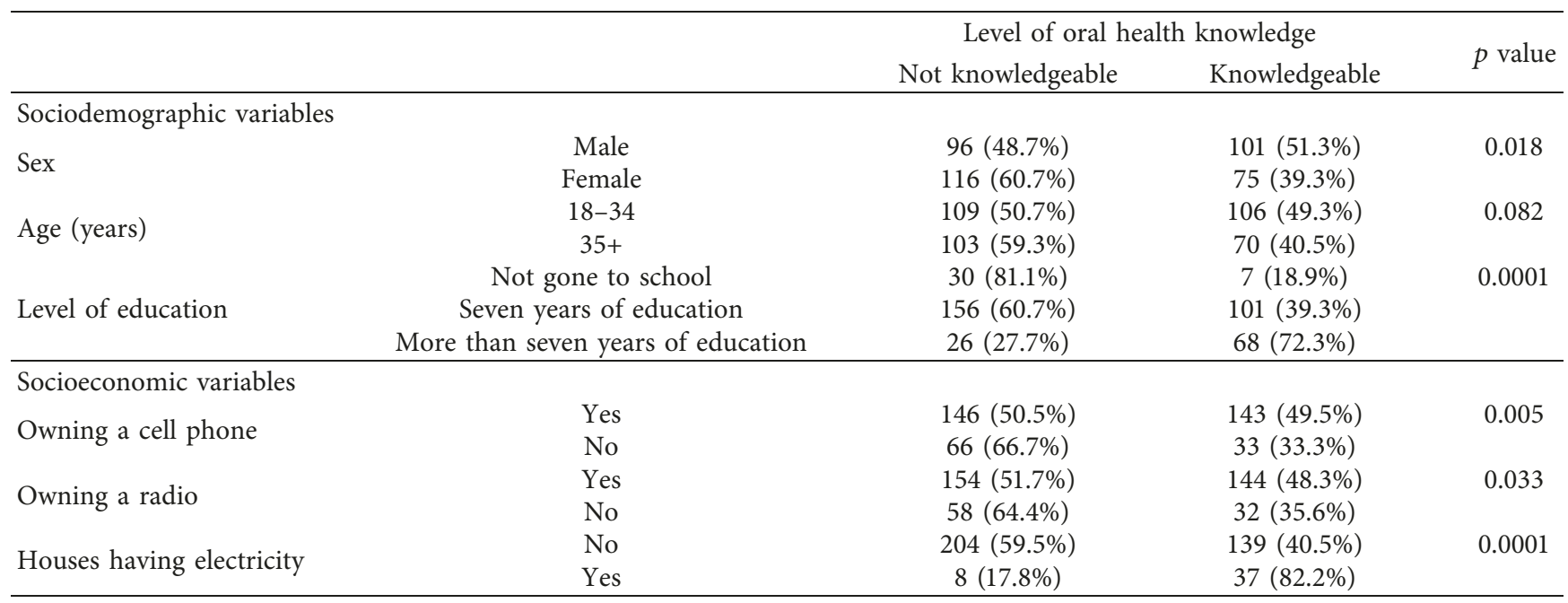

more than seven years of schooling were statistically significantly more knowledgeable $(n=68 ; 72.3 \%)$ on periodontal health when compared to their counterparts ( $p$ value $=0.0001)$. Participants residing in houses having electricity $(n=37$; $82.2 \%)$ had a statistically significantly higher $(p$ value $=0.0001)$ level of knowledge on periodontal health when compared to participants residing in houses not connected to electricity ( $n=139 ; 40.5 \%)$. Participants owning a mobile phone ( $n=143 ; 49.5 \%)$ were statistically significantly more knowledgeable on periodontal health than those who did not own mobile phones $(n=33 ; 33.3 \%)$ with a $p$ value of 0.005 . Compared to those who did not own a radio $(n=32 ; 35.6 \%)$, the ones who owned it $(n=144 ; 48.3 \%)$ were statistically significantly more knowledgeable on periodontal health ( $p$ value $=0.033$.

Table 3 shows the distribution of the participant's level of oral health practices on periodontal health by sociodemographic and socioeconomic variables. Proportionately, there were more male $(n=133 ; 67.0 \%)$ compared to female ( $n=108 ; 56.5 \%)$ participants who had conducive oral health practices $(p=0.034)$. Participants aged $18-34$ years $(n=132 ; 61.4 \%)$ and those aged 35 years and above $(n=108$; $62.4 \%)$ showed no statistical significant differences in their oral health practices $(p=0.835)$. A high statistical significant difference $(p$ value $=0.0001)$ was seen in oral health practices conducive to periodontal health among participants who did not go to school $(n=18 ; 48.6 \%)$, with seven years of education $(n=144 ; 56.0 \%)$, and those with more than seven years of education $(n=78 ; 83.0 \%)$. Practices conducive to oral health were statistically significantly different $(p=0.014)$ among participants who owned $(n=189$; $65.4 \%)$ or did not own a cell phone $(n=51 ; 51.5 \%)$. Owning a radio $(p=0.008)$ or living in houses with electricity $(p=0.019)$ was seen to be a contributing factor towards practices conducive to oral health.

\section{Discussion}

This study assessed the level of knowledge and practices on periodontal health among adults of Misungwi District in
Tanzania using a representative sample of selected clusters of households. These findings are adequate to give some insights into the level of knowledge and practices on periodontal health of adults in Misungwi, Tanzania, and provide baseline data for planning purposes.

With regard to sociodemographic findings of this study, majority of participants were males $(50.8 \%)$ and of the younger age group (55.4\%) and having seven years of education (66.2\%). Studies conducted in Tanzania [25] and Brazil [26] also reported similar findings. Being a developing country, it is expected that the number of young adults compared to older adults in Tanzania will be higher. Furthermore, the higher number of participants with seven years of education could be a reflection of the government efforts to make primary school free and accessible to all [27]. The higher number of males in this study is contrary to findings reported in another study conducted among adults in Tanzania [28]. This difference could be attributed to the differences in study design and sample size.

When we assessed the socioeconomic status as reflected in the 2012 Tanzanian Census (19), the prevalence of the mobile phone and radio ownership was high at 74.5 and $76.8 \%$, respectively, while the percentage of households with a connection to electricity was low at $11.6 \%$.

It is speculated that income generated from either employment, farming, or other business together with reasonable purchasing costs could have enabled the owning of a mobile phone or radio by participants. Furthermore, electricity to the majority of the population in Tanzania is still a challenge and similar to findings reported in this study, and it has been reported that only few households in Tanzania currently have electricity [29]. It is speculated that the few participants who had electricity in their houses had their houses close to an already installed electrical system and hence were able to obtain electricity for a nominal fee.

Assessment of the study participant's knowledge on periodontal health showed that many more could mention signs and symptoms of periodontal diseases (68.6\%) compared to mentioning of any oral disease (49.0\%), causes 
TABLE 3: Distribution of the participant's level of oral health practices on periodontal health by sociodemographic and socioeconomic variables.

\begin{tabular}{lccc}
\hline & & Level of oral health practices & Acceptable value \\
& & Not acceptable & \\
Sociodemographic variables & & & \\
Sex & Male & $65(33.0 \%)$ & $132(67.0 \%)$ \\
& Female & $83(43.5 \%)$ & $108(56.5 \%)$ \\
Age (years) & $18-34$ & $83(38.6 \%)$ & $132(61.4 \%)$ \\
& $35+$ & $65(37.6 \%)$ & $108(62.4 \%)$ \\
Level of education & Not gone to school & $19(51.4 \%)$ & $18(48.6 \%)$ \\
& Seven years of education & $113(44.0 \%)$ & $144(56.0 \%)$ \\
Socioeconomic variables & More than seven years of education & $16(17.0 \%)$ & $78(83.0 \%)$ \\
Owning a cell phone & Yes & $100(34.6 \%)$ & $189(65.4 \%)$ \\
& No & $48(48.5 \%)$ & $51(51.5 \%)$ \\
Owning a radio & Yes & $103(34.6 \%)$ & $195(65.4 \%)$ \\
House having electricity & No & $45(50.0 \%)$ & $45(50.0 \%)$ \\
\end{tabular}

(26.5\%), effects (32\%), and prevention (29.6\%), while about a third (33.2\%) were aware on the harmful effects of smoking on periodontal disease. These findings are comparable to a study conducted in Finland [30]. Contrastingly in the United Kingdom [31] and Kuwait [32], a higher proportion of study participants were knowledgeable on effects of smoking rather than on signs and symptoms of periodontal diseases. Personal experience and observation by participants could have contributed to the reported higher level of knowledge on signs and symptoms of periodontal disease in this study.

Assessed oral health practices on periodontal health by participants reported that the majority (82.7\%) used toothpaste and spend two minutes or more during tooth brushing $(86.6 \%)$ while less than half $(46.4 \%)$ brushed their teeth two or more times a day. The use of toothpaste by majority was also reported by Kikwilu et al. [33]. Similar to results of this study, the general consensus amongst oral healthcare professionals is that individuals should spend at least 2 minutes brushing their teeth with an effective technique at least twice a day [34]. The proportion of participants $(39.7 \%)$ who reported the practice of having attended a dental health facility in the present study was similar to other studies done in Tanzania [25, 35] and different to reports from developed countries like Germany [36] and USA [37]. Furthermore, smoking practiced by a few (15.2\%) participants in this study was similar to results of the standardized estimate of smoking reported in Tanzania by the World Health Organization [38]. The reported oral health practices could be attributed to marketing strategies employed to ensure that toothpaste is readily available at a reasonable cost, lack of availability of a health facility or not having the means to access the service, and personal or social choices made by few who smoke.

Study participants who were males (51.3\%), had more than seven years of education $(72.8 \%)$, residing in houses having electricity $(82.2 \%)$, and who owned a radio $(48.3 \%)$ were statistically significantly more knowledgeable on periodontal health when compared to their counterparts.
Tanzanian males were significantly more knowledgeable about periodontal disease than their female counterparts, which is in agreement with the findings of a previous study conducted in India (34) but in contrast to the results of a Nigerian study (35).

The significant statistical difference in oral health knowledge observed between male and female may be due to inequalities in the opportunity to education within communities which favors males more than females. Furthermore, inequalities in educational opportunities for females could have been contributed to by tradition and culture which favored early marriage of females and early drop out from school due to getting pregnant. It is anticipated that this difference will be decreased in the coming years as the government has made efforts to make primary school free and accessible to all [27].

A highly statistical significant difference $(p$ value $=$ 0.0001 ) was seen in oral health practices conducive to periodontal health between participants who had not gone to school, with seven years of education, and those with more than seven years of education (83.0\%). Other studies [39, 40] have also reported the level of education as a strong determinant of oral hygiene practices. Furthermore, the level of education was suggested as a potential risk indicator for oral health practices $[41,42]$. Being educated probably gives one the foundation and basis of understanding and the ability to make decisions with regard to practices conducive to oral health.

Owning a radio $(p=0.008)$, a mobile phone $(p=0.014)$, or living in houses with electricity $(p=0.019)$ was seen to be a contributing factor towards practices conducive to oral health. The observed findings could have been contributed to by participants having adequate knowledge on oral health that heightened the observed practices. In addition, the observed oral healthcare practices could have been enabled by the interlinking of the various socioeconomic variables. Furthermore, ownership of the mobile phones or radios can be used in future as a means of assessment of knowledge and practices on oral health within a community. 


\section{Conclusions}

Participants in this study who were males, owned a mobile phone, owned a radio, resided in houses having electricity, and having more than seven years of education were more knowledgeable and had more conducive oral health practices on periodontal health. These findings can be used to develop strategies for oral health promotion and control of periodontal diseases in the country.

\section{Data Availability}

Data will be made available on request by contacting the corresponding author.

\section{Conflicts of Interest}

The authors declare that they have no conflicts of interest.

\section{Acknowledgments}

The authors would like to acknowledge the Catholic University of Health and Allied Sciences (CUHAS)/Bugando Medical Centre (BMC) Research Ethical Committee (CREC) for providing the ethical clearance to conduct this study. Sincere gratitude is also extended towards the Misungwi District authorities and participants for their acceptance to participate in this study. Misungwi district authority provided the necessary funding to conduct this study.

\section{References}

[1] R. G. Watt and P. E. Petersen, "Periodontal health through public health--the case for oral health promotion," Periodontology 2000, vol. 60, no. 1, pp. 147-155, 2012.

[2] W. J. Loesche and N. S. Grossman, "Diagnosis and treatment periodontal disease as a specific, albeit chronic infection," Clinical Microbiology Reviews, vol. 14, no. 4, pp. 727-752, 2001.

[3] D. F. Kinane and R. Attström, "Advances in the pathogenesis of periodontitis. Group B consensus report of the fifth European Workshop in Periodontology," Journal of Clinical Periodontology, vol. 32, no. 6, pp. 130-131, 2005.

[4] G. C. Armitage, "Periodontal diagnoses and classification of periodontal diseases," Periodontology 2000, vol. 34, no. 1, pp. 9-21, 2004.

[5] I. Needleman, C. McGrath, P. Floyd, and A. Biddle, "Impact of oral health on the life quality of periodontal patients," Journal of Clinical Periodontology, vol. 31, no. 6, pp. 454-457, 2004.

[6] B. L. Pihlstrom, B. S. Michalowicz, and N. W. Johnson, "Periodontal diseases," The Lancet, vol. 366, no. 9499, pp. 1809-1820, 2005.

[7] P. E. Petersen, D. Bourgeois, H. Ogawa, S. Estupinan-Day, and C. Ndiaye, "The global burden of oral diseases and risks to oral health," Bulletin of the World Health Organization, vol. 83, no. 9, pp. 661-669, 2005.

[8] Y. A. Aljehani, "Risk factors of periodontal disease: review of the literature," International Journal of Dentistry, vol. 2014, Article ID 182513, 9 pages, 2014.

[9] P. E. Petersen, "Global policy for improvement of oral health in the 21st century--implications to oral health research of World Health Assembly 2007, World Health Organization,"
Community Dentistry and Oral Epidemiology, vol. 37, no. 1, pp. 1-8, 2009.

[10] S. S. Kadtane, "Periodontal health status of different socioeconomic groups in out-patient department of TMDC and RC, moradabad, India," Journal of Clinical and Diagnostic Research, vol. 8, no. 7, pp. ZC61-ZC64, 2014.

[11] J. Smits and R. Steendijk, "The international wealth index (IWI)," Social Indicators Research, vol. 122, no. 1, pp. 65-85, 2015.

[12] T. US Department of health and human services, Oral Health in America: A Report of the Surgeon General, National Institute of Dental and Craniofacial Research, Bethesda, MD, USA, 2000

[13] R. Deinzer, W. Micheelis, N. Granrath, and T. Hoffmann, "More to learn about: periodontitis-related knowledge and its relationship with periodontal health behaviour," Journal of Clinical Periodontology, vol. 36, no. 9, pp. 756-764, 2009.

[14] H. Löe, "Oral hygiene in the prevention of caries and periodontal disease," International Dental Journal, vol. 50, no. 3, pp. 129-139, 2000.

[15] P. Axelsson, B. Nyström, and J. Lindhe, "The long-term effect of a plaque control program on tooth mortality, caries and periodontal disease in adults: results after 30 years of maintenance," Journal of Clinical Periodontology, vol. 31, no. 9, pp. 749-757, 2004.

[16] C. N. J. Egelberg, "Role of mechanical dental plaque removal in prevention and therapy of caries and periodontal diseases," in Proceedings of European Workshop on mechanical plaque control, pp. 190-247, Berne, Switzerland, May 1998.

[17] K. B. Hill, B. Chadwick, R. Freeman, I. O'Sullivan, and J. J. Murray, “Adult Dental Health Survey 2009: relationships between dental attendance patterns, oral health behaviour and the current barriers to dental care," British Dental Journal, vol. 214, no. 1, pp. 25-32, 2013.

[18] T. Y. Eid Ma, "A clinical trial on the effectiveness of professional tooth-brushing using dentifrice and water," Odontostomatol Trop, vol. 14, no. 2, pp. 9-12, 1991.

[19] L. C. Carneiro and M. N. Kabulwa, "Dental caries, and supragingival plaque and calculus among students, tanga, Tanzania," ISRN Dentistry, vol. 2012, article 245296, 6 pages, 2012.

[20] P. T. Lembariti B.S, J. E. Frenken, Prevalence and severity of periodontal conditions among adults in urban and rural Morogoro, Tanzania," Community Dentistry and Oral Epidemiology, vol. 16, no. 4, pp. 240-243.

[21] Ministry of Health and Social Welfare, Oral Health. Guide for Health Care Providers at Reproductive and Child Health Clinic, Central Oral Health Unit, Dar es Salaam, Tanzania, 2003.

[22] Ministry of Health and Social Welfare, Policy Guidelines for Oral Health Care in Tanzania Dar es Salaam, Ministry of Health and Social Welfare, Dar es Salaam, Tanzania, 2010.

[23] N. M. C. Luhanga, "Geriatric oral health issues in Africa: Tanzanian perspective," International Dental Journal, vol. 51, no. 3, pp. 219-227, 2001.

[24] 2012 Population and Housing Census Population Distribution by, 2013.

[25] E. N. Kikwilu, J. R. Masalu, F. K. Kahabuka, and A. R. Senkoro, "Prevalence of oral pain and barriers to use of emergency oral care facilities among adult Tanzanians," BMC Oral Health, vol. 8, no. 1, pp. 1-7, 2008.

[26] M. de L. C. Bonfim, F. F. Mattos, E. F. e Ferreira, A. C. V. Campos, and A. M. D. Vargas, "Social determinants 
of health and periodontal disease in Brazilian adults: a crosssectional study," BMC Oral Health, vol. 13, no. 1, p. 22, 2013.

[27] R. Rajani and G. Omondi, The Primary Education Development Plan (PEDP), A Summary, HakiElimu Working Paper Series No. 6, p. 1, 2003.

[28] S. K. Singh, O. S. Stanslaus, and H. V. Aroon, "Occurrence of dental caries among the adults attending a regional referral hospital in Tanzania," Journal of Orofacial Research, vol. 4, no. 1, pp. 30-34, 2014.

[29] World Bank, Increasing Electricity Access in Tanzania to Reduce Poverty, http://www.worldbank.org/en/.../increasingelectricity-access-in-tanzania-to-reduce-poverty.

[30] A. J. Markkula and H. Murtomaa, "Conceptions of Finnish people about the etiology and prevention of dental caries and periodontal disorders," Community Dentistry and Oral Epidemiology, vol. 5, no. 3, pp. 108-115, 1977.

[31] M. Terrades, W. A. Coulter, H. Clarke, B. H. Mullally, and M. Stevenson, 'Summary of: patients' knowledge and views about the effects of smoking on their mouths and the involvement of their dentists in smoking cessation activities," British Dental Journal, vol. 207, no. 11, pp. 542-543, 2009.

[32] K. F. Al-Shammari, M. A. Moussa, J. M. Al-Ansari, and Y. S. Al-Duwairy, "Dental patient awareness of smoking effects on oral health: comparison of smokers and nonsmokers," Journal of Dentistry, vol. 34, no. 3, pp. 173-178, 2006.

[33] E. N. Kikwilu, J. E. Frencken, and J. Mulder, "Utilization of toothpaste and fluoride content in toothpaste manufactured in Tanzania," Acta Odontologica Scandinavica, vol. 66, no. 5, pp. 293-299, 2008.

[34] A. Gallagher, "The effect of brushing time and dentifrice on dental plaque removal in vivo," Journal of Dental Hygiene, vol. 83, no. 3, pp. 111-116, 2009.

[35] J. R. Masalu, E. N. Kikwilu, F. K. Kahabuka, A. R. Senkoro, and I. A. Kida, "Oral health related behaviors among adult Tanzanians: a national pathfinder survey," BMC Oral Health, vol. 9, no. 1, pp. 1-9, 2009.

[36] F. Erdsiek, D. Waury, and P. Brzoska, "Oral health behaviour in migrant and non-migrant adults in Germany: the utilization of regular dental check-ups," BMC Oral Health, vol. 17, no. 1, pp. 5-7, 2017.

[37] T. P. Wall, M. Vujicic, and K. Nasseh, "Recent trends in the utilization of dental care in the United States," Journal of Dental Education, vol. 76, no. 8, pp. 1020-1027, 2012.

[38] WHO, World Health Organization Report on the Global Tobacco Epidemic, Country Profile: United Republic of Tanzania, pp. 1-2, vol. II, World Health Organization, Geneva, Switzerland, 2007.

[39] M. Chen, R. M. Andersen, D. E. Barmes, M. H. Leclerq, and C. S. Lyttle, Comparing oral health care systems: a second international collaborative study, World Health Organization, Geneva, Switzerland, 1997.

[40] P. E. Petersen, Inequalities in Oral Health: The Social Context for Oral Health, Quintessence, London, UK, 2007.

[41] Y. Jiang, C. A. Okoro, J. Oh, and D. L. Fuller, "Sociodemographic and health-related risk factors associated with tooth loss among adults in Rhode Island," Preventing Chronic Disease, vol. 10, article 110285, 2013.

[42] J. B. Park, K. Han, Y. G. Park, and Y. Ko, "Association between socioeconomic status and oral health behaviors: the 20082010 Korea national health and nutrition examination survey," Experimental and Therapeutic Medicine, vol. 12, no. 4, pp. 2657-2664, 2016. 


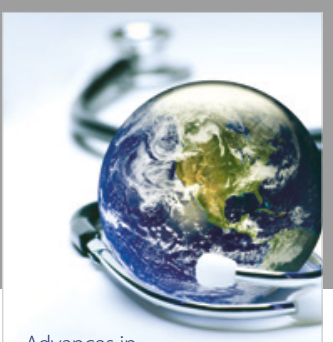

Advances in
Public Health

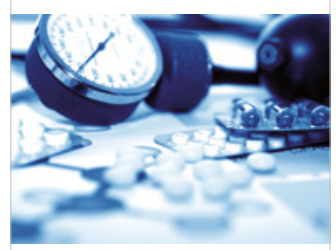

Case Reports in

Medicine

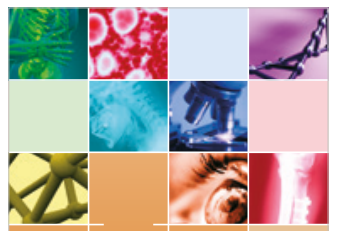

niernational Journal of

Biomaterials
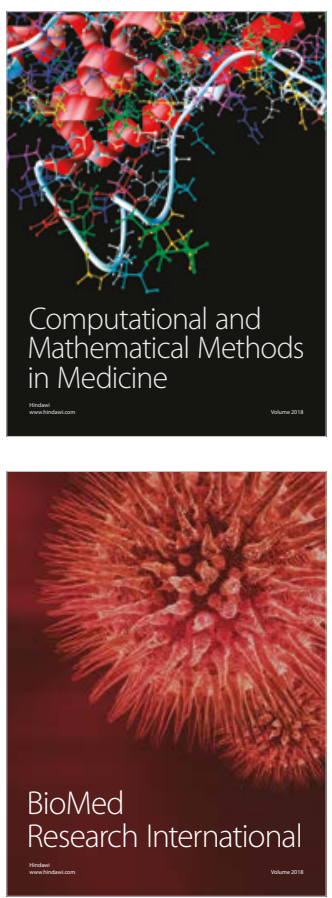

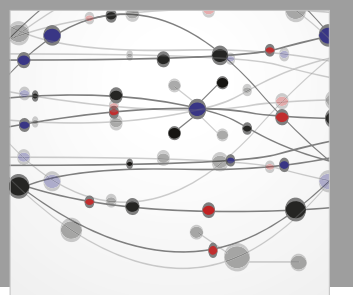

The Scientific World Journal Dentistry

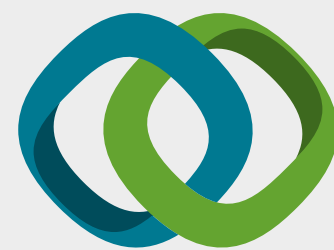

Hindawi

Submit your manuscripts at

www.hindawi.com
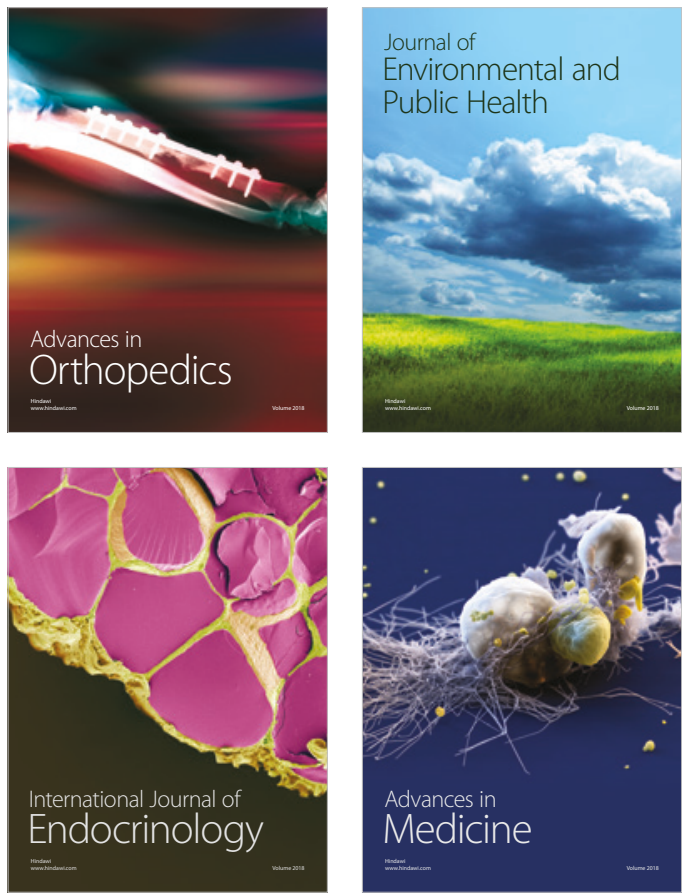
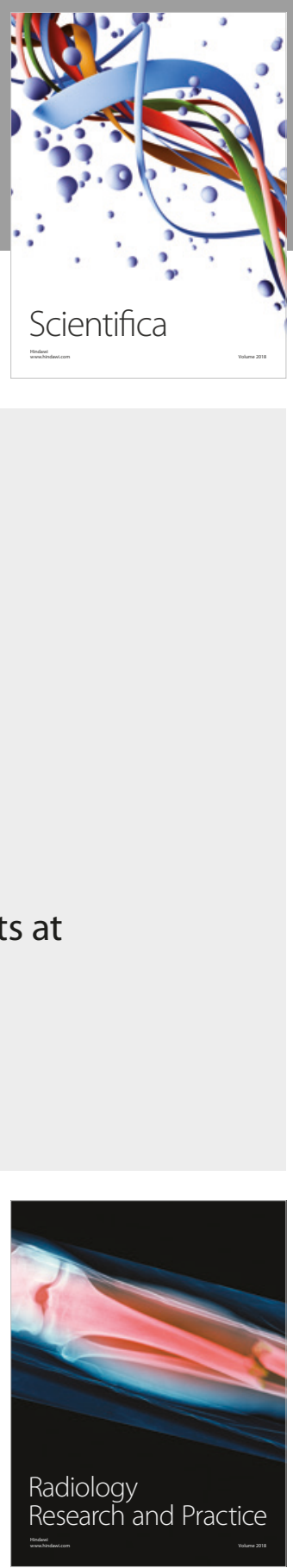

Scientifica

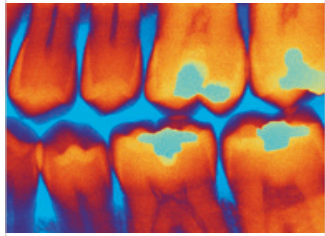

Case Reports in

Dentistry
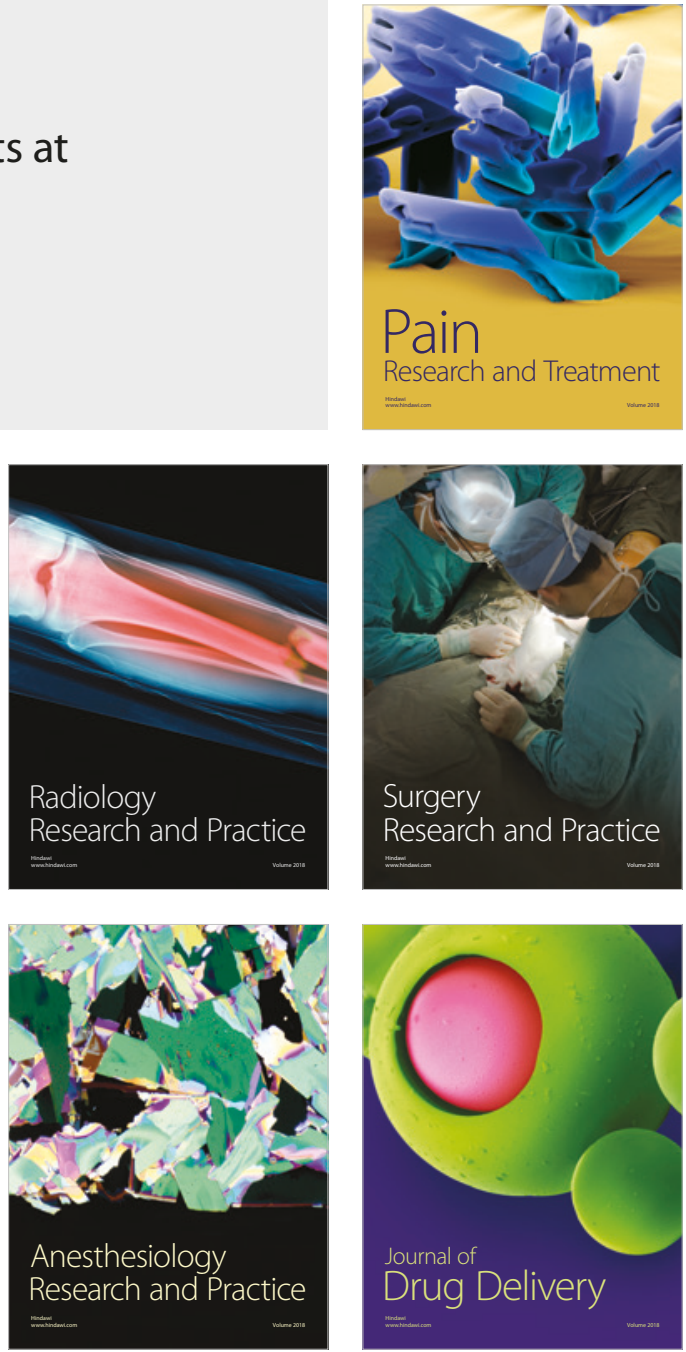